NORDIC JOURNAL

\title{
Bokrecension: Dörte Hansens Altes Land (Körsbärslandet) och Mittagsstunde (Middagstimmen)
}

\section{Thorsten Päplow}

\section{Universitetet i Agder}

Med sin första roman Altes Land (2015) ${ }^{1}$ lyckades Dörte Hansen $(* 1964)$ övertyga både de tyska kritikerna och sina läsare. Så till den grad att boken översattes bl. a. till svenska, norska och danska inom ett resp. två år. Även en tv-produktion (2020, ZDF) följde relativt raskt. Hennes andra roman Mittagsstunde $(2018)^{2}$ fortsatte denna succé - där väntas även en filmversion bli släppt under 2022. Många läsare ser otåligt fram emot Hansens tredje roman. Precis som i de första två tror man att den tredje romanen kommer att utspela sig i den nordvästliga delen av Tyskland, kulturellt och språkligt med en del plattyska inslag.

\section{Altes Land/Körsbärslandet}

Hansens första roman, Körsbärslandet, publicerades 2015 mot bakgrund av den s k flykting- eller migrationskrisen. Därmed inte sagt att timingen var avsiktlig. Men flykten och förlusten av hembygden, av 'Heimat', är ett av flera centrala teman i boken. Den börjar med att Hildegard von Kamcke och dottern Vera 1945 kommer från Ostpreussen till 'Altes Land', ett område i närheten av Hamburg som är känt för sina fruktodlingar: "Marscherat åstad som preussare och anlänt som slödder.” (Hansen, 2016, s. 121) Under den strapatsrika flykten till fots tvingas de lämna Veras ihjälfrusna lillebror i sin barnvagn vid vägrenen; de ser hela familjer som hängt sig i träd längs vägen eller hoppat i iskalla floder; de hör hästar som skriar i dödsångest, när isen brister under dem och de dras ned i vattnet av den kärra de är fastspända vid. Allt detta blir bestående minnen, för att inte säga trauman, för huvudpersonen Vera. När de väl kommer fram till den gård i Altes Land, där de anvisats inkvartering, blir de allt annat än välkomnade med ord som: "Hur många fler polacker skulle det komma egentligen?" (Hansen, 2016, s. 7), eller: "Flüchtlingspack, Lü̈s op'n Nack'."’3 (Hansen, 2015, s. 163)

Alla flyktens vedermödor beskrivs dock ytterst sparsamt i Altes Land. Däremot utgör de bakgrunden till den familjehistoria, som berättas i fyra generationer. Det är framför allt de decennielånga traumatiska efterverkningarna av krig och flykt som Hansen beskriver:

\footnotetext{
${ }^{1}$ Svensk översättning: Körsbärslandet (2016); dansk och norsk översättning Kirsebcerlandet (2016, resp. 2017).

${ }^{2}$ Svensk översättning: Middagstimmen (2019).

${ }^{3}$ Egen översättning (med nödrim, som fungerar bättre på plattyska): "Flyktingpacke' - har löss på nacke’".
} 
Somliga hade tagit till rakkniven, ett rep eller något gift, fast det var först senare, för att de inte längre stod ut med de eländiga gestalter som de kommit att bli.

Men det flesta hade inte tillåtit sig att dö utan förblivit vandrare sjuka av hemlängtan livet ut. (Hansen, 2016, s. 121)

Många flyktingar, bland dem Vera och hennes mor, förblir "[d]rivis, alltid kall, ogripbar" (Hansen, 2016, s. 125) för partners, bekanta och barn, som föddes efter flykten. Metaforer och liknelser kring is och kyla återkommer gång på gång i boken och markerar den avgrund som ligger öppen inom de fyra generationerna i Altes Land: mellan dem som tvingades utstå och se allt det 'obegripligt' hemska under flykten 1944/45 och dem, som föddes senare och för vilka föräldrarna eller de äldre syskonen för alltid förblev 'o(be)gripliga', distanserade och kalla:

Kvinnorna hade tvingats bli hjältar eller djur, annars skulle de aldrig ha klarat sig över isen. Hur skulle de någonsin kunna sjunga visor för barnen efter det, eller skratta tillsammans med dem?

De var inte den sortens mödrar längre. De ville inte lyssna, de berättade ingenting, förklarade ingenting, de sökte inte ens efter ett språk att uttrycka det outsägliga med, de övade sig i att glömma och blev bra på det. Fortsatte sin vandring i sina kappor av is, för dem behövde man inte förklara vad stelning4 var. (Hansen, 2016, s. 190)

Altes Land är dock inte en genommörk bok, även om Hansen slår an en dyster och allvarlig grundton. Beskrivningen av den fåordiga och egensinniga nordtyska lantbefolkningen ger en del 'comic relief'. Det gör även stadsborna, som flyttat från Hamburg ut till Altes Land och leker 'lantisar' eller rentav gör sig till förståsigpåare för vad de uppfattar som den lite stolliga och excentriska 'urbefolkningen'. Just detta är dock inte enbart humoristiska inslag för att luckra upp stämningen. Nej, här introducerar Hansen ett tema, som utforskas mer ingående i hennes andra roman, Mittagsstunde, även om den inte är någon uppföljare i konventionell mening.

\section{Mittagsstunde/Middagstimmen}

Även Mittagsstunde utspelar sig i norra (Väst-)Tyskland, närmare bestämt i Nordfriesland, strax söder om danska Sønderjylland. I denna roman får vi följa hur en familj utvecklas under flera generationer

\footnotetext{
${ }^{4}$ Egentligen: "Erstarrungswärme" (stelningsvärme; Hansen, 2015, s. 271).
} 
samtidigt som byn Brinkebülls öde återspeglas. Genom en landreform 1965 förvandlas Brinkebüll successivt från en levande by på landet, som funnits och vuxit fram genom århundraden, till en 'spökby'. Berättelsen pendlar mellan ett då (runt 1965) och ett nu (ca. 2015). I nutiden är genomsnittsåldern hög hos Brinkebüll-borna, eftersom de unga till stor del flyttat därifrån, till exempel den 47-årige huvudpersonen Ingwer Feddersen, som arbetar vid universitetet i Kiel. De nedstängda delarna av 'bykroppen' - skolan, mataffären, bageriet, mejeriet - speglas i bybefolkningens åldersrelaterade successiva nedbrytning och 'sönderfall' (jfr. Hansen, 2019, s. 95). Detta illustreras bl.a. av Ingwer Feddersens mormor, Ella, som i nutid uppvisar tydliga tecken på demens:

Ella stack ofta annars, [...] gick ut på gatan utan rollator, i handen en lapp eftersom hon skulle till Boysens bageri och till Dora Koopmanns affär. Hon vadade i rinnande vatten där människor, tider, platser drev runt som de ville. Att man inte hade kunnat handla i byn på tjugo år, stämde möjligen i de andras värld. I Ellas värld dök småsystrar upp igen och hade aldrig varit döda. Den gamla skolan fanns plötsligt igen, korna i hagen bakom hennes hus och en ung man som hette Krischan. Kvarndammen var inte igenfylld längre, mejeriet ännu inte nedlagt. Och Marret, sjutton år gammal, sjöng fortfarande i Brinkebüllsalen. I en ärmlös klänning, som Heidi Brühl. (Hansen, 2019, s. 38-39).

För resten av världen är byn inte längre mer än ett landskap. Rent praktiskt och i överförd betydelse utgör detta ett existentiellt hot för gamla Ella liksom för resten av byborna och bykulturen som hade vänts överända under efterkrigstidens moderniseringsiver: "Bilarna körde fort genom Brinkebüll, ingen höll sig till 50-skylten, fortsatte bara på femmans växel. En landsvägsby, ingen anledning att växla ner, inget ställe att stanna på. Ingenting för en nittiotvååring som vadade runt $i$ ett annat århundrade, uppå landsvägen, i en blå städrock” (Hansen, 2019, s. 39).

Men nedbrytningen av Brinkebüll börjar, om man så vill, med en dubbel våldtäkt: 1965 skickas tre ingenjörer från centralt håll (förmodligen från delstatshuvudstaden Kiel) till Brinkebüll för att som lantmätare förbereda och driva igenom en jordreform, där den komplicerade strukturen av små och delvis icke-sammanhängande åkrar och ängar, som uppstått genom århundraden av intrikata familjära delningar och arvsskiften, skall utplånas och effektiveras med några penndrag. Varefter ingenjörerna försvinner tillbaka till staden. Medan dessa tre 'våldför' sig på byn, gör även en av dessa lantmätare en starkt utvecklingshämmad flicka med barn. Det som vi med dagens rättsmedvetande skulle se som ett slags våldtäkt, uppfattas i Brinkebüll dock snarare som en skam för flickans familj och hanteras, som så mycket annat, med byns främsta problemlösningsverktyg: det tigs ihjäl - så gott det nu går. Men i 
byn kallas barnet som följde av övergreppet, karaktären Ingwer Feddersen, alltid "Ingwer Lantmätare" (Hansen, 2019, s. 124) - bakom hans rygg, förstås.

Liksom Mittagsstunde väcker associationer till Siegfried Lenz Deutschstunde (1968; Tysktimmen $)^{5}$, så väcker Hansens roman även associationer till Lenz So zärtlich war Suleyken (1955; Så kärleksfull var Suleyken), vars berättelser på ett ofta humoristiskt sätt och i ett slags mosaik skildrar en svunnen bykultur i Masurien (i f d Ostpreussen). En av de mindre episoderna i Mittagsstunde, som vävs in i den övergripande romanhandlingen, påminner om den kärleksfullt humoristiska tonen $\mathrm{i}$ Suleyken och handlar om byns präst. Pastor Ahlers, som på mer än ett sätt kommer utifrån och som trots "många års tjänstgöring i den nordfrisiska provinsen", har fått förlika sig med att det finns gränser för hur mycket den kyrkliga auktoriteten kan tränga igenom ett lantligt samhälle som envist lever efter sina egna, oskrivna regler:

Gud skulle veta att han verkligen hade försökt vederkvicka själarna och befria dem ur dödsskuggans dal, men herdejobbet här var svårt. Fåren i hans flock verkade vara impregnerade mot all form av tro. Vindtät allväderspäls, inget fromt trängde igenom den. Allt gudomligt rann bara av som vatten på en gås. De trodde inte ett ord av det han sa. Men de trodde lika lite på Marrets undergångar. Tokor och präster fick prata på helt enkelt. (Hansen, 2019, s. 39)

Men bortsett från några humoristiska passager kring den lite stolliga bybefolkningen, som kan läsas som en aktualiserad version av So zärtlich war Suleyken, fastnar ett initialt skratt mestadels i halsen. Man kan som läsare misstänka att det här rör sig om en medveten strategi - dvs. att Dörte Hansen använder sig av klichéer eller stereotyper - t.ex. om fåordiga, lite råbarkade, men i grunden godhjärtade nordtyskar - för att sedan avslöja att det bakom klichéfasaden ligger något annat. ${ }^{6}$

Ett exempel på detta är episoden med Heiko Ketelsen, en skolkamrat till huvudpersonen Ingwer, under det Brinkebüllska 1970-talet. Det hela börjar med en lätt humoristisk skildring kring hur Heiko i det karga nordtyska landskapet utvecklar en något säregen faiblesse för amerikansk countrymusik, USA:s ökenpräglade söder samt linedance. Redan som barn låtsas han att grannbondens ponny är en "vild mustang" och går i vuxen ålder klädd i cowboystövlar och sitt "mustangprydda skärpspänne" (Hansen, 2019, s. 71). I Brinkebüll kallas han därför i smyg för "de Sheriff" (Hansen, 2019, s. 70). Men genom Ingwers minnen blir det snart tydligt att cowboy-faiblessen inte bara är en stollig eller

\footnotetext{
${ }^{5}$ Det fiktiva Brinkebüll i Mittagstunde ligger i samma nordfrisiska område som det fiktiva Rugbüll i Lenz Deutschstunde.

${ }^{6}$ Jfr. även Peter Bichsels utforskning av klichéer som litterär teknik (Bichsel, 1982, s. 48-49).
} 
'bonnig' förkärlek, utan ett sätt att redan som ung försöka undkomma det för ett Brinkebüllskt barn oundvikliga:

Då såg han [Ingwer; T. P.] Heikos rygg framför sig igen, hans armar, hans nacke och hans blåslagna ansikte, ena ögat igenmurat, ibland till och med båda. Innan det hade blivit de Sheriff av honom, hade hans smeknamn varit Fakir-Heiko. Folkert Ketelsen slog sina söner varje dag, utan någon speciell anledning. Knuffade dem ur vägen eller nedför trappan, drev dem genom huset och genom ladugården, och när ingen son fanns i närheten slog han djuren. Brinkebüllborna hörde hans kreatur bröla varje dag, och då visste de att Folkert Ketelsen var i ladugården. Så länge djuren brölade, var det åtminstone inte barnen eller hustrun.

Heiko var yngst av de tre bröderna, men den ende som aldrig grät. Honom kunde man slå hur länge man ville, han skrek inte. (Hansen, 2019, s. 73-74)

Och som om detta inte vore illa nog, avslöjas i detta återigen Brinkebüll-bornas oförmåga och ovilja (jfr. också kapitlet "titta inte dit” i Altes Land) att hantera situationen på annat sätt än på de treapornas-manér, genom att inte se, höra eller tala:

Ingen människa i byn hade någonsin tänkt tanken att man borde hjälpa honom mot pappan. Visst tyckte alla att Folkert Ketelsen var en odugling, man ondgjorde sig över den där skitstöveln. Hade medlidande med barnen, stack till dem choklad ibland, en kaka, bjöd dem på läsk när det var Barnens dag. Och lät dem gå hem igen när festen var slut, hem till piskan, tjurkäppen och läderbältet. Man lade sig inte i, eftersom Folkert Ketelsen var en Brinkebüllbo, bymänniska, med en gammal gård, hade alltid bott här, far, farfar och farfarsfar. Ingwer funderade på vad man som Brinkebüllbo måste ställa till med för att bli utesluten. Innan folk slutade hälsa, innan inbjudningarna till festerna slutade komma och Dora Koopmann vägrade betjäna en i butiken. Han kom inte på något. [...]

Heiko hade visst aldrig riktigt återvänt från Vilda västern, han fortsatte helt enkelt att spela sin roll. (Hansen, 2019, s. 73-74)

Visst, det finns omsorg, kärlek, gemytlighet och en viss stollig fryntlighet hos människorna i Brinkebüll - som liksom själva byn fr o m 1960-talet faller offer för en maktfullkomlig och moderniseringsorienterad centralförvaltning. Det är en myndighet som inte bryr sig om det intrikata samspelet i Brinkebüll eller bykulturen, som vuxit fram över århundraden. Ja, sådan är den bild som målas upp i Mittagsstunde. Samtidigt lägger Hansen en mosaik där bitarna allt eftersom även formar 
en skräckbild av Brinkebüll som en 'dödsskuggans dal' av häpnadsväckande allmän våldsbenägenhet, mörklagda skandaler, skambeläggande, förljugenhet, missunnsamhet, instängdhet och mycket mer - i kombination med en utpräglad tystnadskultur.

\section{Facit}

Som bör ha framkommit är varken Altes Land (Körsbärslandet) eller Mittagsstunde (Middagstimmen) 'lättviktig underhållning'. Ändå är romanerna lättlästa. Med en nästan lakonisk och till synes flyhänt berättarstil, som aldrig glider över i patos eller effektsökeri, lyckas Dörte Hansen teckna komplexa bilder av människor och utvecklingsmönster i ett motsägelsefullt Nordtyskland. Den som kan anbefalles läsa böckerna i original, eftersom en del av de nordtyska 'kryddningen' (bl.a. de plattyska inslagen) lätt går förlorad i de annars så vällyckade översättningarna av Christine Bredenkamp resp. Anna Hörmander Plewka.

\section{Källor}

Bichsel, P. (1982). Der Leser. Das Erzählen - Frankfurter Poetik-Vorlesungen. Suhrkamp.

Hansen, D. (2015). Altes Land. Albrecht Knaus Verlag.

Hansen, D. (2016). Körsbärslandet (C. Bredenkamp, övers.). Bokförlaget NoNa.

Hansen, D. (2018). Mittagsstunde. Penguin Verlag.

Hansen, D. (2019). Middagstimmen (A. Hörmander Plewka, övers.). Bokförlaget Nona. 